\title{
NEW CONTROL STRATEGY TO ALLOW THE PHOTOVOLTAIC SYSTEMS OPERATION UNDER GRID FAULTS
}

\author{
Gustavo M. S. Azevedo ${ }^{1}$, Pedro Rodriguez ${ }^{2}$, Marcelo C. Cavalcanti ${ }^{1}$, \\ Gerardo Vázquez ${ }^{2}$, Francisco A. S. Neves ${ }^{1}$ \\ (1) Universidade Federal de Pernambuco (UFPE) - Departamento de Engenharia Elétrica e Sistemas de Potência \\ Recife, Pernambuco, Brazil, Emails: gustavomsa@aim.com, marcelo.cavalcanti@ufpe.br, fneves@ufpe.br \\ (2) Universitat Politècnica de Catalunya (UPC) - Departament d'Enginyeria Elèctrica \\ Barcelona, Spain, Email: prodriguez@ee.upc.edu, gerardo.vazquez@upc.edu
}

\begin{abstract}
This paper presents a new control strategy that allows the photovoltaic system operation under grid faults without overcurrent and assuring grid sinusoidal currents. The current limiter is made indirectly by using an active power limiter that is calculated dynamically based on the grid positive-sequence voltage. The paper also shows that the classic control strategies used in the PV systems cause harmonic current injections on the electrical grid and dangerous overcurrents when voltage sags occur. The strategy presented here overcomes these drawbacks and allows the inverter operation under any unbalanced condition. The control is made on stationary reference frame using Proportional-Resonant current control. This new control strategy is compared to the classic strategy through simulations in PSCAD/EMTDC and the experimental results prove its effectiveness.
\end{abstract}

Keywords - Distributed generation, Fault current limiters, Photovoltaic systems.

\section{INTRODUCTION}

Nowadays the overall power system is changing, with many Distributed Generation (DG) units, such as wind turbines, Photovoltaic (PV) modules and fuel cells, being developed and installed. In several countries the PV systems power supplied to the electrical grid is having more visibility due to many governmental incentives. The PV system is particularly attractive as a renewable source for DG units due to its relative small size, noiseless operation, simple installation and the possibility to put it close to the user. The development of grid-connected systems is demanding a better evaluation of the performance of the available PV systems under fault conditions, as well as the quality of the energy generated by them. For this reason, the grid connection of power converters in DG systems, should be carefully designed and controlled in order to achieve an optimal operation of the generation plants under generic circumstances [1].

There are many power converter topologies for PV systems such as two-stages [2][3] or single-stage [3][4], and with transformer or transformerless [5]. However all these topologies require an inverter to connect them to the grid and several requirements must be met to perform this connection. One of these requirements is about the voltage protection. The Germany standard DIN/VDE 0126 [6], for example, says that overvoltage higher than $15 \%$ and undervoltage lower than $20 \%$ must lead to the disconnection from the grid within $200 \mathrm{~ms}$. On the other hand, disconnection of DG units from the system "at first sign of trouble" might not be the optimal approach. Repeated disconnections may have a negative impact on components' lifetime as well as may cause further disturbances on the grid [7]. Thus the lifetime and reliability of the whole system can be improved if the inverter is able to keep the unit connected as long as possible. However, none of the commercial PV inverters tested in [7] was able to do it.

This paper shows that the control strategies used in the PV systems cause harmonic current injections on the grid and dangerous overcurrents when voltage sags occur. Therefore, trip protections are necessary to avoid the PV inverter damage. This paper proposes a new control strategy to overcome these drawbacks and to allow the inverter operation under any unbalanced condition. The control is made on stationary reference frame using ProportionalResonant (PR) current control that assures zero steady-state error [8]. The dc link voltage is controlled by using the active power delivered by the PV system. Instead of using a hard saturation on reference currents, the control calculates dynamically the maximum active power that the inverter can deliver, using this value as limit to the reference power. The current references are calculated based on the positivesequence voltage in such a way to result in balanced values even in presence of unbalanced grid voltages. The positivesequence voltage and the grid frequency information is obtained by a Phase-Locked Loop (PLL) based on a Dual Second Order Generalized Integrator for Quadrature-Signals Generation (DSOGI-QSG) [9]. The new strategy is evaluated through simulations in PSCAD/EMTDC and the experimental results prove its effectiveness.

\section{PV SYSTEM CONTROL}

Figure 1 shows a generic diagram of a single-stage PV system. Basically, it is composed of a PV array, a Voltage Source Inverter (VSI), a LC filter to connect the inverter to the grid and the control system. The first control block is a Maximum Power Point Tracking (MPPT) used to set the point of PV array operation in such a way to maximize its power generation [10]. The MPPT output is the dc voltage reference used by the dc link voltage controller. The controller of the dc link voltage can act on the direct current, in the controllers based on synchronous reference frame $[4][11][12]$, or on the active power, in the controllers based on stationary reference frame [13].

Generally the PV system control is designed considering only the balanced and sinusoidal condition which results in errors under fault situations. 


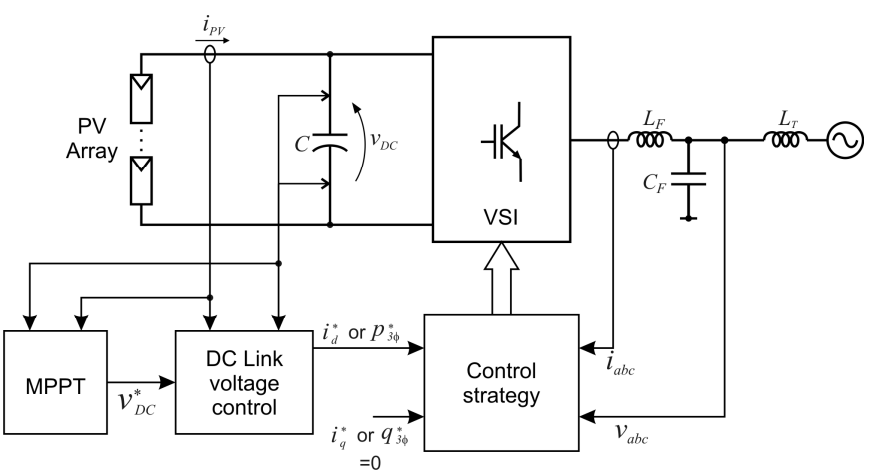

Fig. 1 Diagram of the PV system

The errors can appear due to PLL synchronization system and the oscillation on Proportional Integral (PI) controllers references. However there are some ways to overcome these problems, as enhanced PLL strategies, current controls in a double synchronous reference frame or PR controllers.

On the other hand, the main drawback of these controls is the overcurrent that occurs due to grid unbalanced voltage. The dc link voltage control is generally designed to keep the $\mathrm{dc}$ voltage equal to the reference in any condition. It means that the active power is always constant and it results in distorted currents when the voltage is unbalanced. Figure 2 shows an example with the PV system (using the classic control strategy) when an asymmetrical fault occurs. Information about the simulation conditions will be described in the next section. In this example the overcurrent is $51 \%$ and the currents are completely distorted during the fault. Note that both dc voltage and active power are constant at any time as mentioned before. An improvement can be obtained if the dc voltage controller is designed to allow oscillations on dc voltage. The overcurrent, in this case, decreases to $22 \%$ and the currents become sinusoidal.

\section{PROPOSED CONTROL}

The instantaneous active power delivered by the inverter is given by

$$
p=\mathbf{v} \cdot \mathbf{i}
$$

where $\mathbf{v}=\left(v_{a}, v_{b}, v_{c}\right)$ is a voltage vector, $\mathbf{i}=\left(i_{a}, i_{b}, i_{c}\right)$ is a current vector and $\cdot$ represents the scalar product. For a given voltage vector, there are infinite current vectors, which are able to deliver exactly the same instantaneous active power to the grid. The current vector that results in sinusoidal currents is given by [14]:

$$
\mathbf{i}_{p}^{*}=\frac{P}{\left|\mathbf{v}^{+}\right|^{2}} \mathbf{v}^{+}
$$

where $P$ is the average active power and $\mathbf{v}^{+}$is the positivesequence voltage vector.

The current vector in (2) consists of a set of balanced positive-sequence sinusoidal waveforms. Under unbalanced operating conditions, the instantaneous active power that is delivered to the grid will differ from $P$ because of the interaction between the injected positive-sequence current and the negative-sequence grid voltage, i.e.,

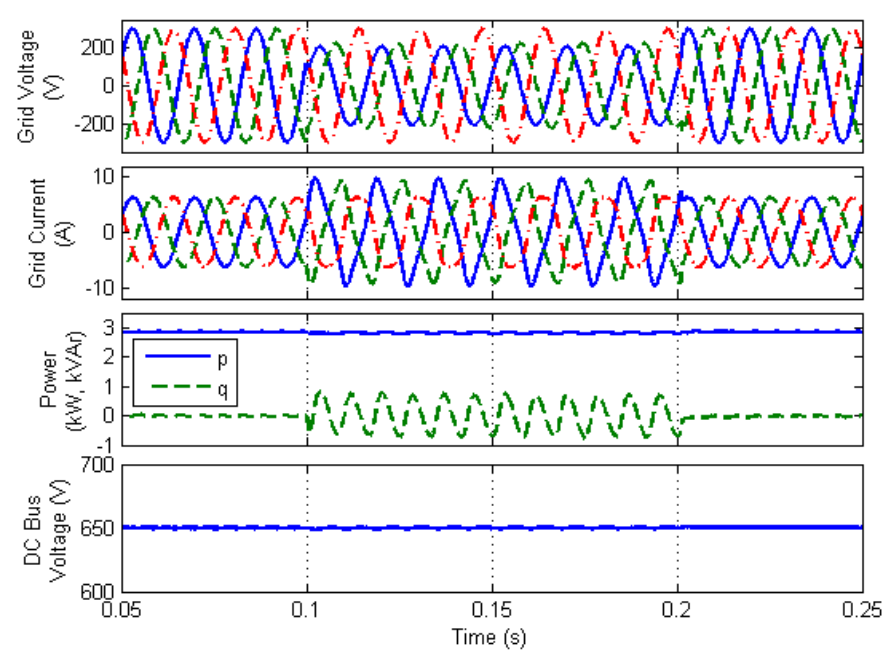

Fig. 2 Simulation results of the classic PV control strategy under a phase-neutral fault. (a) grid voltages, (b) currents delivered by PV system, (c) instantaneous active and reactive powers, (d) dc link voltage.

$$
p=\mathbf{v} \cdot \mathbf{i}_{p}^{*}=\underbrace{\mathbf{v}^{+} \cdot \mathbf{i}_{p}^{*}}_{P}+\underbrace{\mathbf{v}^{-} \cdot \mathbf{i}_{p}^{*}}_{\tilde{p}}
$$

where $\tilde{p}$ is the power oscillation at twice the fundamental grid frequency. The instantaneous reactive power can be calculated as

$$
q=\left|\mathbf{v} \times \mathbf{i}_{p}^{*}\right|=\underbrace{\left|\mathbf{v}^{+} \times \mathbf{i}_{p}^{*}\right|}_{0}+\underbrace{\left|\mathbf{v}^{-} \times \mathbf{i}_{p}^{*}\right|}_{\tilde{q}}
$$

where $\tilde{q}$ is also oscillating at twice the fundamental grid frequency.

The dc voltage control has slow dynamic and the active power reference will be considered constant in each gridvoltage cycle. As the vector $\mathbf{v}^{+}$has constant amplitude, the reference current vector will have constant amplitude. This amplitude is given by

$$
\hat{I}=\frac{2}{3} \frac{P}{\hat{V}^{+}}
$$

where the symbol ${ }^{\wedge}$ denotes peak value. In (5), it is possible to define the maximum power

$$
P_{\text {LIMIT }}=\frac{3}{2} \hat{I} \hat{V}^{+}
$$

that can be delivered to the grid keeping the current amplitude, $\hat{I}$ (inverter limits). Note that the limit is a function of positive sequence voltage and any fault that results in a reduction of this value will decrease the average power delivered by the inverter. The development is made in a generic coordinate system and it can be used in any reference frame.

\section{A. Implementation of proposed control}

The block diagram of the proposed control is shown in Fig. 3. The first block is the dc link voltage control. The dc voltage reference is generated by the MPPT algorithm, which was omitted in this diagram. 


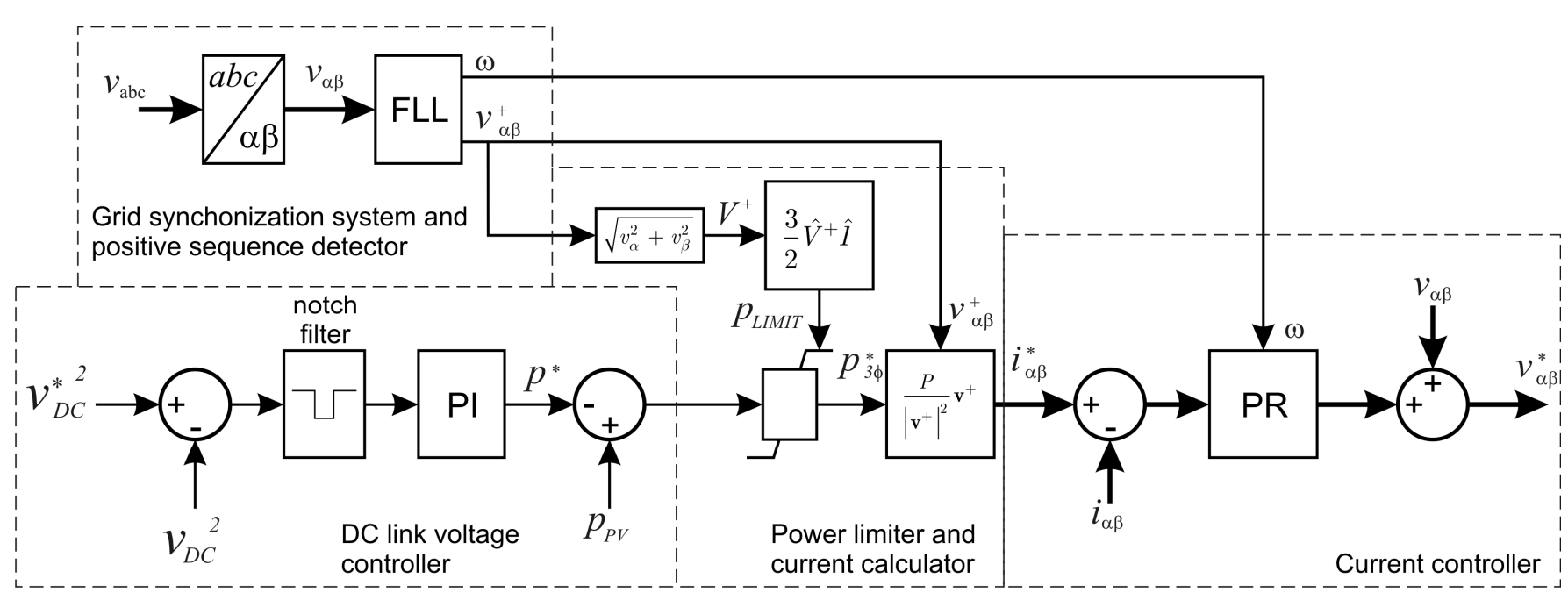

Fig. 3 Overall diagram of the proposed controller and its sub-blocks.

The square dc voltage error is used instead of the dc voltage error in such a way to find a linear control loop. The square dc voltage error is applied to a PI controller, resulting in an active power reference. The PV power generation is added to this reference to have the inverter total active power reference. A notching filter tuned at twice fundamental frequency is used to disregard the dc bus oscillation that occurs under fault conditions. The saturation limit of the power reference is not hard and must change in function of the positive-sequence voltage, in (6), to keep the current limit. After the saturation block the reference current is calculated using (2).

To calculate the power limit and current references it is necessary to get the grid positive-sequence voltage and its angular frequency to perform the current control. This information about the grid voltage and frequency can be obtained by using the Frequency-Locked Loop (FLL) proposed in [9]. It is a simple way to get the positive alphabeta components of the grid voltage and the system frequency even if the grid voltages are unbalanced. This grid synchronization system results from the application of the instantaneous symmetrical components method on the stationary alpha-beta reference frame. The SOGI is used to generate in-quadrature signals in the alpha-beta frame.

The current control is made in the stationary reference frame using a PR controller. The basic functionality of the PR controller is to introduce an infinite gain at a selected resonant frequency for eliminating steady-state error at that frequency, and it is conceptually similar to an integrator whose infinite dc gain forces the dc steady-state error to zero [8]. The resonant part of the PR controller can be viewed as a generalized integrator (GI). The transfer functions of the GI and the complete PR controller are given by

$$
\begin{gathered}
G_{A C}=\frac{2 K_{i} S}{S^{2}+\omega^{2}}, \\
G_{P R}=K_{p}+\frac{2 K_{i} S}{S^{2}+\omega^{2}},
\end{gathered}
$$

where $K_{i}$ is the integral gain, $K_{p}$ is the proportional gain and $\omega$ is the resonant frequency. The output of the PR controller is added to grid voltage, $v_{\alpha \beta}$, that perform a feed-forward control loop and then it is the reference to the PWM.

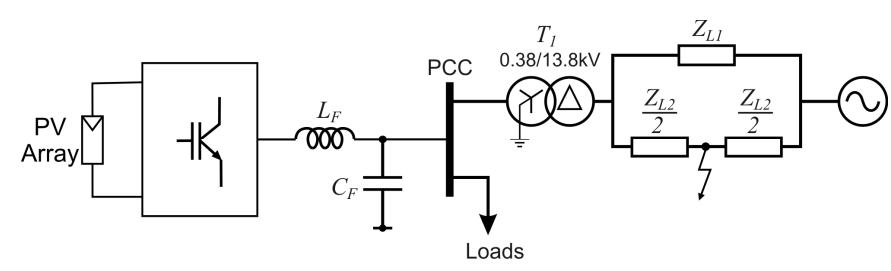

Fig. 4 Model of the system used in simulation.

TABLE I

System parameters used in the simulation

\begin{tabular}{cc}
\hline Parameter & Value \\
\hline dc link capacitance & $500 \mu \mathrm{F}$ \\
\hline Inductance of the output filter, $\mathrm{L}_{\mathrm{f}}$ & $3 \mathrm{mH}$ \\
\hline Capacitance of the output filter, $\mathrm{C}_{\mathrm{f}}$ & $0.375 \mu \mathrm{F}$ \\
\hline Proportional gain of the dc link controller & 0.04 \\
\hline Integral gain of the dc link controller & 2 \\
\hline Proportional gain of the current controller, $\mathrm{K}_{\mathrm{p}}$ & 50 \\
\hline Integral gain of the current controller, $\mathrm{K}_{\mathrm{i}}$ & 25 \\
\hline Set point of the current limiter, $\hat{I}$ & $6.5 \mathrm{~A}$
\end{tabular}

\section{B. Simulation results}

The performance of the proposed control has been tested in simulations carried out in PSCAD/EMTDC, where a $3 \mathrm{~kW}$ PV system is connected to a $380 \mathrm{~V}$ grid at the Point of Common Coupling (PCC). The grid is modeled by a source connected to the transformer $\mathrm{T}_{1}$ through two lines that are represented by their equivalent impedances, $\mathrm{Z}_{\mathrm{L} 1}$ and $\mathrm{Z}_{\mathrm{L} 2}$. The whole system is shown in Fig. 4. The system and control parameters are shown in Table I.

In order to analyze the behavior of the proposed strategy in a faulty scenario, a phase to ground fault is applied at midpoint of the line 2, generating type B voltage sag at this node [15]. The voltages at PCC are show in Fig. 5a. It was assumed that the inverter is delivering rated power, with rated current, when the fault occurs. The current limit was set to the same value of rated current (6.5 A of peak). Therefore it can be noted that the current peak value does not change even under the fault as shown in Fig. 5b. Moreover, the currents are sinusoidal and balanced. Figure 5c shows the active and reactive power delivered by de PV system. During the fault these powers are oscillating due to the interaction 
between the voltage negative-sequence and the current positive-sequence. The average reactive power is zero as desired, but the average active power is lower than the value before the fault. It occurs because the voltage positivesequence decreases and the control have to decrease the power to do not exceed the rated current. The output power decreases, but the PV power tends to remain constant. Therefore the dc bus voltage increases, as shown in Fig. 5d, and consequently the PV power decreases due to the output characteristic of the PV cell. The same simulation is repeated assuming that the power generated by the PV array is lower than the power in the first case. The results are shown in Fig. 6. The power delivered to the grid is constant and equal to $1.58 \mathrm{~kW}$ before the fault. It becomes oscillatory during the fault but its average value is the same as before. In this case the active power does not decrease because the inverter is supplying this power without reaching the rated current. Thus the current amplitude increases because of the reduction in the voltage positive-sequence.

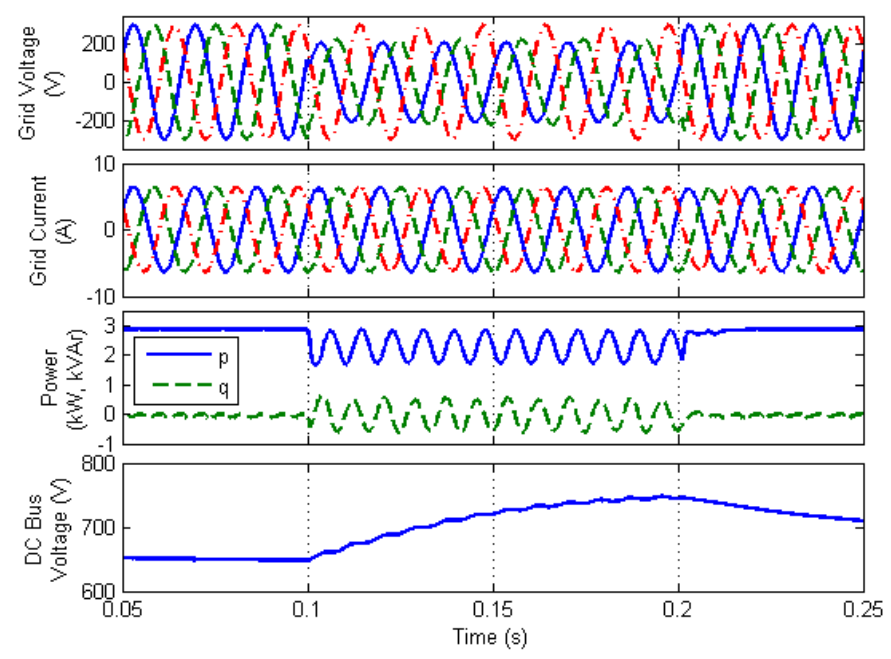

Fig. 5. Proposed control system when it is delivering nominal current: (a) Grid voltages, (b) Currents delivered by the PV system, (c) Instantaneous active and reactive powers, (d) dc link voltage.
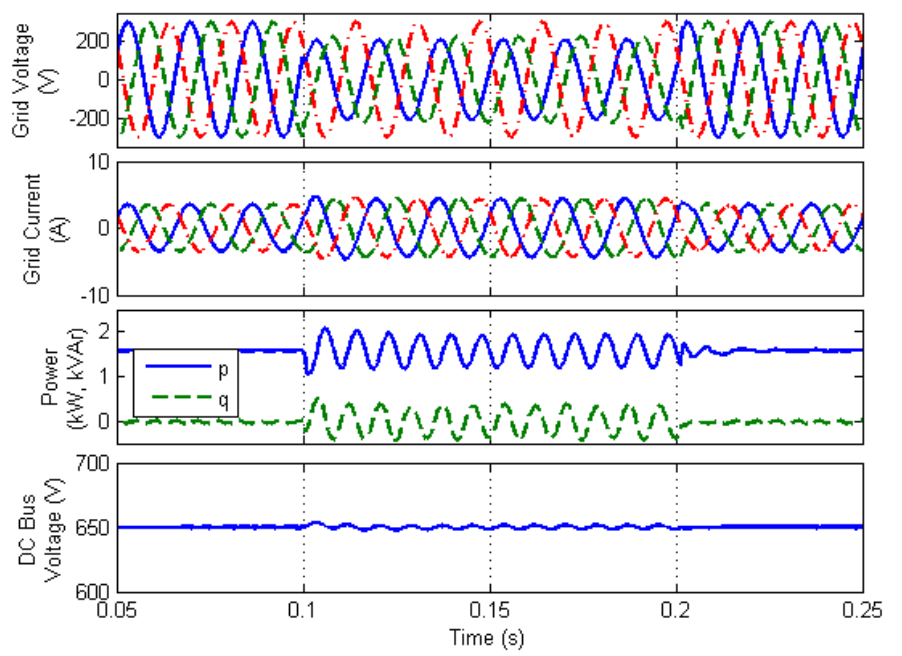

Fig. 6. Proposed control system when it is delivering low power: (a)

Grid voltages, (b) Currents delivered by the PV system, (c)

Instantaneous active and reactive powers, (d) dc link voltage.

\section{EXPERIMENTAL RESULTS}

The control strategies have been implemented in an experimental setup, similar to that shown in Fig. 4, with a current-controlled VSI and a LC filter connected to the grid through a $\Delta y$ transformer. Moreover the grid consists of another transformer with taps. The fault was generated by switching the tap of the grid transformer, generating voltage sag of $50 \%$ in phase $c$. This single-phase fault (dip type B) is propagated to the $y$ winding of the transformer as a dip type C. The voltage at PCC was $70 \mathrm{~V}(\mathrm{rms})$ before the fault. The PV array was represented by a dc-power source, which was set to $300 \mathrm{~V}$, in order to evaluate only the current limiter strategy.

A dSpace 1103 DSP card was used to implement the current limiter controller, the FLL for detecting the voltage positive-sequence and the algorithm to calculate the current references in the synchronous reference frame. The sampling frequency is set to $20 \mathrm{kHz}$ and switching frequency is set to $10 \mathrm{kHz}$.

Figure 7a shows the voltage at PCC and the currents injected by the inverter. The current scale is $1 \mathrm{~A} / \mathrm{V}$. The power delivered by the inverter was set to result in a peak of $5 \mathrm{~A}$ and the current limit, $\hat{I}$, was set to the same value. Therefore when the fault occurs the current is kept below the limit value. The active and reactive powers are shown in Fig. $7 \mathrm{~b}$. Note that during the fault the active power is oscillating and its average value is $730.6 \mathrm{~W}$. Before the fault the average value was $870.2 \mathrm{~W}$. It occurs due to the voltage positivesequence during the fault be lower than the voltage before the fault. Consequently to keep the current peak, the average active power must be lower, as suggest in (6).

To evaluate the effectiveness of the strategy, the experiment was repeated with the current limiter inactive during the first $60 \mathrm{~ms}$ after the fault. When the dip occurs the current peak increase around $16 \%$ because the current limiter was inactive and return to $5 \mathrm{~A}$ as soon as it is enabled, as shown in Fig. 8a. Figure $8 \mathrm{~b}$ shows that the average active power during the $60 \mathrm{~ms}$ after the dip is the same as before resulting in overcurrents. The value of the currents is proportional to the sag in the voltage positive-sequence. Thus for most severe faults the overcurrents reach higher values than that shown in Fig. 8b.

\section{CONCLUSION}

This paper proposes a control strategy for three-phase photovoltaic systems connected to the electrical grid. The proposed control allows the inverter operation in any fault situation without overcurrents and delivering sinusoidal currents. Its implementation is as simple as classic strategies and it can be applied to other distributed generation systems since the power of the primary source can be limited. The effectiveness of the proposed control strategy is evaluated through simulation in PSCAD and experimental results.

\section{ACKNOWLEDGEMENT}

The author would like to thank CAPES and CNPq for their financial support. 


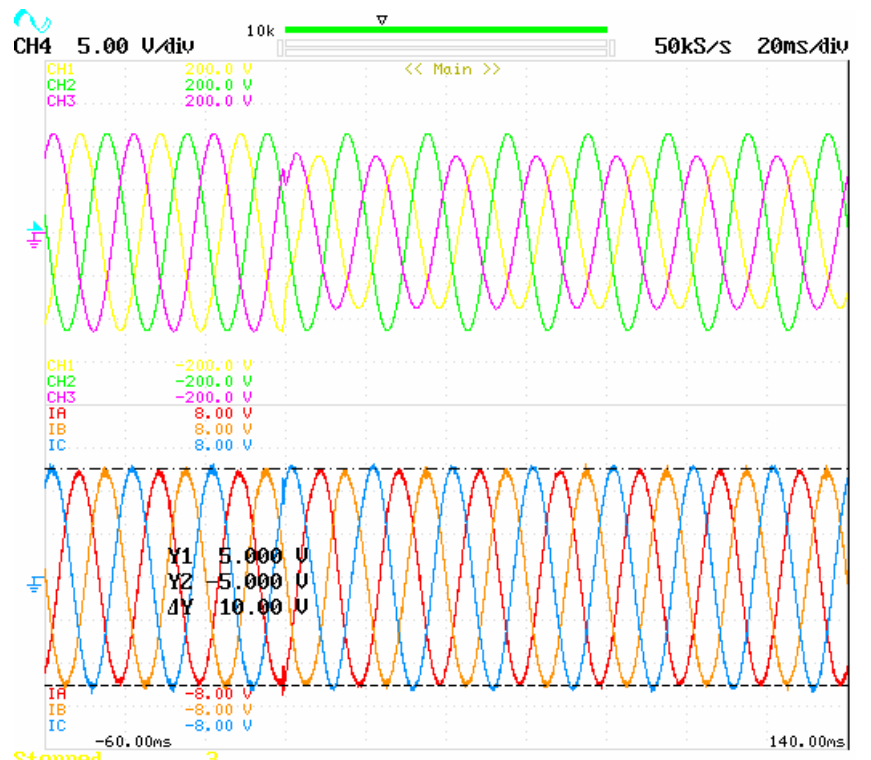

(a)

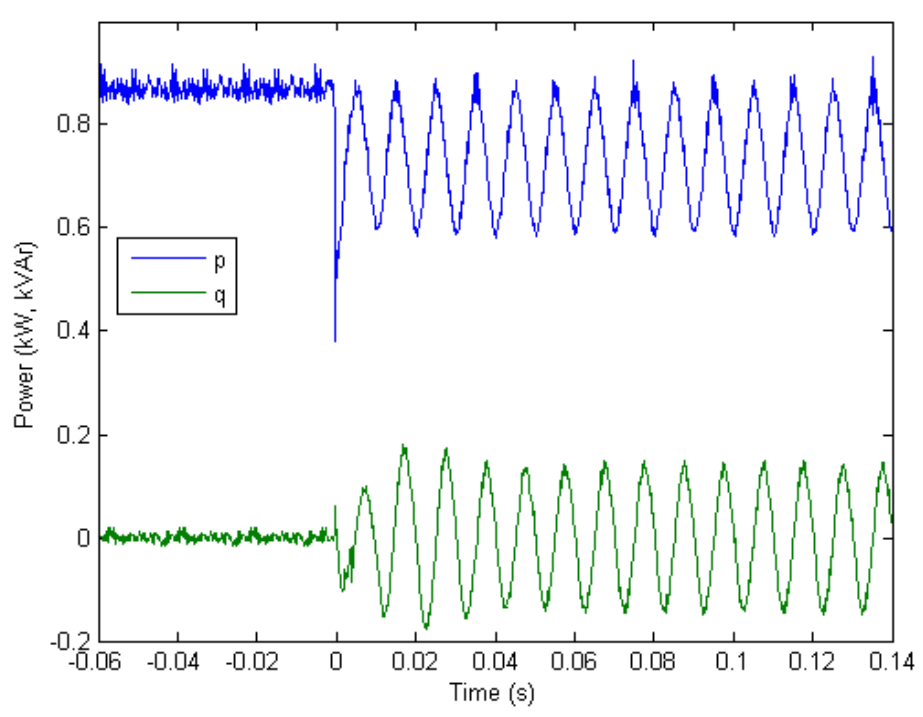

(b)

Fig. 7. Experimental results of the proposed control system with a dip type C: (a) Grid voltages and currents, (b) Active and reactive powers delivered to the grid.

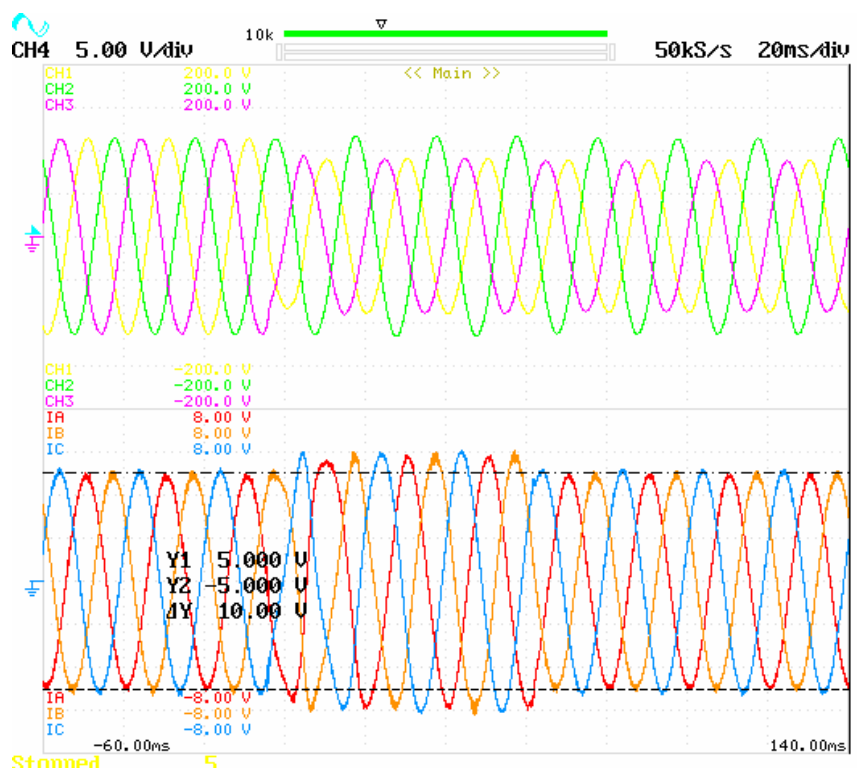

(a)

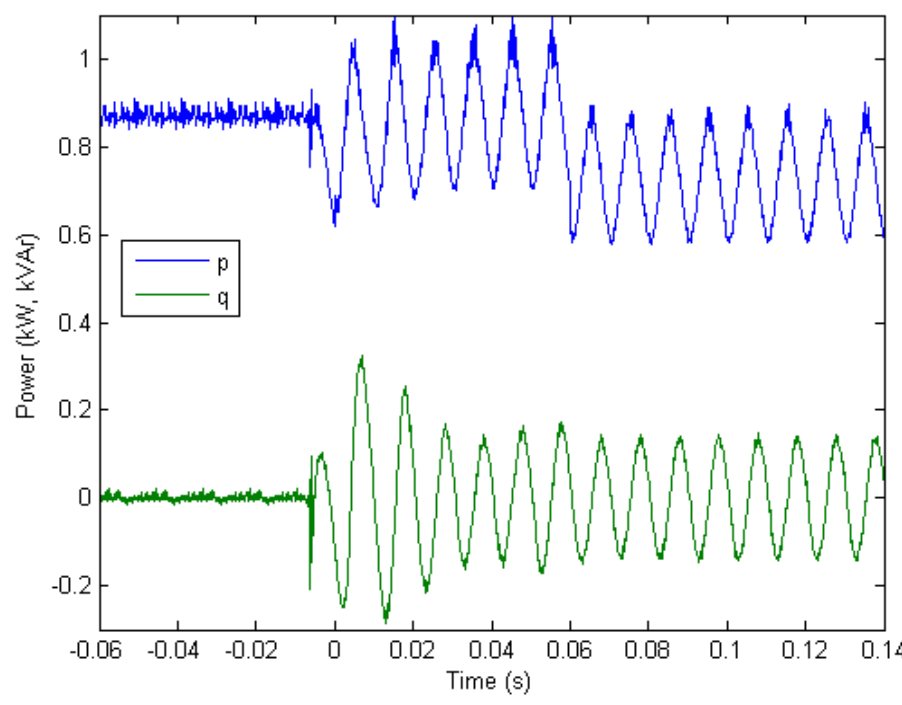

(b)

Fig. 8. Experimental results of the control system with a dip type $\mathrm{C}$ and the control limit disabled in the first $60 \mathrm{~ms}$ after the fault: (a) Grid voltages and currents, (b) Active and reactive powers delivered to the grid.

\section{REFERENCES}

[1] F. Iov and F. Blaabjerg, "Converter applications in future european electricity network," UNIFLEX-PM 019794 (SES6), Tech. Rep., 2006.

[2] Casaro, M. M., Martins, D.C., "Grid-connected PV system: Introduction to behavior matching," Power Electronics Specialists Conference, 2008. PESC 2008. IEEE , vol., no., pp.951-956, 15-19 June 2008

[3] Kjaer, S.B.; Pedersen, J.K.; Blaabjerg, F., "Power inverter topologies for photovoltaic modules-a review," Industry Applications Conference, 2002. 37th IAS
Annual Meeting. Conference Record of the , vol.2, no., pp. $782-788$ vol.2, 2002

[4] Azevedo, G. M. S., Cavalcanti, M. C., Neves, F A. S., Rodriguez, P., "Implementation of a grid connected photovoltaic system controlled by digital signal processor," In: Congresso Brasileiro de Eletronica de Potencia, 2007, Blumenau. COBEP2007. Blumenau, 2007

[5] Kerekes, T.; Teodorescu, R.; Klumpner, C.; Sumner, M.; Floricau, D.; Rodriguez, P., "Evaluation of threephase transformerless photovoltaic inverter topologies," Power Electronics and Applications, 2007 European Conference on , vol., no., pp.1-10, 2-5 Sept. 2007 
[6] VDE 0126-1-1, Automatic disconnection device between a generator and the public low-voltage grid

[7] B. Bletterie, R. Bründlinger, H. Fechner; "Sensitivity of photovoltaic inverters to voltage sags - test results for a set of commercial products;" International Conference on Electricity Distribution, 2005, Turin, Italien

[8] Teodorescu, R.; Blaabjerg, F.; Liserre, M.; Loh, P.C., "Proportional-resonant controllers and filters for gridconnected voltage-source converters," Electric Power Applications, IEE Proceedings - , vol.153, no.5, pp.750762, September 2006

[9] Rodriguez, P.; Luna, A.; Ciobotaru, M.; Teodorescu, R.; Blaabjerg, F., "Advanced Grid Synchronization System for Power Converters under Unbalanced and Distorted Operating Conditions," IEEE Industrial Electronics, IECON 2006 - 32nd Annual Conference on , vol., no., pp.5173-5178, 6-10 Nov. 2006

[10] Esram, T.; Chapman, P.L., "Comparison of Photovoltaic Array Maximum Power Point Tracking Techniques," Energy conversion, IEEE transactions on , vol.22, no.2, pp.439-449, June 2007

[11] Cavalcanti, M. C.; Azevedo, G. M. S.; Amaral, B. A.; Oliveira, K. C.; Neves, F A. S.; Lins, Z. D., "A Grid
Connected Photovoltaic Generation System with Harmonic and Reactive Power Compensation," In: Congresso Brasileiro de Eletronica de Potencia, 2005, Recife. COBEP2005. Recife, 2005.

[12] Schonardie, M.F.; Martins, D.C., "Grid-connected Photovoltaic Three-phase System Using Park Transformation With Active And Reactive Power Control And Input Voltage Clamped," In: Congresso Brasileiro de Eletronica de Potencia, 2007, Blumenau. COBEP2007.

[13] Komatsu, Y., "Application of the extension pq theory to a mains-coupled photovoltaic system," Power Conversion Conference, 2002. PCC Osaka 2002. Proceedings of the , vol.2, no., pp.816-821 vol.2, 2002

[14] Rodriguez, P.; Timbus, A.V.; Teodorescu, R..; Liserre, M..; Blaabjerg, F.., "Flexible Active Power Control of Distributed Power Generation Systems During Grid Faults," Industrial Electronics, IEEE Transactions on, vol.54, no.5, pp.2583-2592, Oct. 2007.

[15] M. H. J. Bollen and L. D. Zhang "Different methods for classification of three-phase unbalanced voltage dips due to faults," Electric Power Systems Research Vol. 66, Issue 1, July 2003, Pages 59-69 